C2020. Licensed under the Creative Commons Attribution-NonCommercial-NoDerivatives 4.0 International http://creativecommons.org/about/downloads

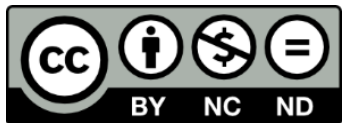

DOI of final article - https://doi.org/10.1016/j.actaastro.2020.04.028 


\title{
Plasma-Assisted Ignition and Combustion of Lean and Rich Air/Fuel Mixtures in Low- and High-Speed Flows
}

\author{
M.P. Bulat ${ }^{1}$, P.V. Bulat ${ }^{1,2, *}$, P.V. Denissenko ${ }^{3}$, I.I. Esakov ${ }^{4}$, L.P. Grachev ${ }^{4}$, \\ P.V. Lavrov ${ }^{4}$, K.N. Volkov ${ }^{5}$, I.A. Volobuev ${ }^{2}$ \\ ${ }^{1}$ Baltic State Technical University, 190005, St Petersburg, Russia \\ ${ }^{2}$ ITMO University, 197101, St Petersburg, Russia \\ ${ }^{3}$ University of Warwick, CV4 7AL, Coventry, United Kingdom \\ ${ }^{4}$ Moscow Radiotechnical Institute of Russian Academy of Sciences, 117519, Moscow, Russia \\ ${ }^{5}$ Kingston University, SW15 3DW, London, United Kingdom
}

\begin{abstract}
A stabler ignition and combustion of the premixed air/fuel mixture remains a topic of great interest due to the high demand for effective and efficient propulsion systems in aerospace applications. Extensive experimental studies and numerical simulations have been carried out to understand and develop ignition systems using cold and non-thermal plasma in microwave streamer discharges. Use of sub-critical streamer discharge allows to ignite air/fuel mixture by an external electric field whose intensity is significantly lower than the intensity required to induce air breakdown. Ignition and combustion of air/propane mixture by microwave sub-critical streamer discharge in low- and high-speed flows is studied experimentally. Qualitative (flame structure) and quantitative (size of combustion region, temperature distributions) characteristics of the flame zone are provided for different flow speeds and equivalence fuel/air ratios, and conditions of discharge initiation with metallic microwave vibrator are studied. The streamer discharge makes it possible to create multiple ignition points providing almost instantaneous ignition of entire volume of the mixture. The results show that the sub-critical streamer discharge can potentially be used in various applications providing more rapid and efficient combustion.
\end{abstract}

\section{Keywords}

Flight safety; Plasma-assisted ignition; Microwave discharge; Streamer discharge; Combustion control; Propulsion; Air/fuel ratio

\section{Introduction}

A stabler ignition and combustion of the premixed air/fuel mixture remains a topic of great interest due to the high demand for effective and efficient propulsion systems in aerospace applications. Reliability of ignition system and combustion control are strongly coupled with flight safety. Extensive experimental, theoretical and numerical studies have been carried out for past years to test various ignition technologies (e.g., electric discharges, microwave discharges, laser pulses) and to understand and develop ignition systems using cold and nonthermal plasma [1-6]. Plasma-assisted technologies for supersonic combustion are reviewed

\footnotetext{
*Corresponding author: pavelbulat@mail.ru
} 
in [7-11]. These studies demonstrated the potential of plasma-assisted technologies in various fields to improve combustion stability, air and fuel mixing, flow control. However, complexity and correlation of various physical processes with a wide range of temporal and spatial scales make it difficult identification of dominant pathway affecting combustion in highspeed flows [12]. Application of the microwave discharge in the jet engine would allow one to considerably improve its characteristics and to expand its operating range [13-15]. In the internal combustion engines, conventional spark plug ignition has some limitations associated with difficulties of ignition of lean or diluted mixtures.

In practical application, difficulties of ignition and combustion control in high-speed flows are governed with relative large characteristic ignition and combustion times. Various types of plasma discharges have shown promising characteristics in different applications including flow control in aerodynamics [16], ignition and combustion in propulsion engineering [17-20], stabilization of flames [23-25]. Characteristic propane ignition and combustion times in the supersonic flow with Mach number 2 could be decreased up to factor $2-5$ by plasma-assisted combustion $[17,18]$. The propulsive performance of air-breathing pulse detonation engines has been theoretically and numerically studied over a wide range of system configurations, operating parameters and flight conditions [26,27].

In the real engine, the microwave discharge has to be realized in the high-speed flows. The streamer channels of its composition have their typical velocity of growth that lies in the range $10^{5}-10^{6} \mathrm{~cm} / \mathrm{s}$. The problems arising at development of a jet engine for a high-speed flight can potentially be solved with creation of the microwave discharge in a focus of an electromagnetic beam. However, development of freely localized electrodeless microwave discharge at high pressures requires high levels of microwave energy in the beam. For example, the air breakdown at pressure 760 torr takes place at intensity of the microwave beam $10^{6} \mathrm{~W} / \mathrm{cm}$. In this case, a local discharge is induced with special facilities. Then, the microwave streamer discharge spreads in a considerable volume of the microwave beam. Use of sub-critical streamer discharge allows to ignite air/fuel mixture by an external electric field whose intensity is significantly lower than the intensity required to induce air breakdown [13-15].

There are various types of microwave discharges used in practical applications. Microwave discharges for a fixed wavelength are divided into a number of categories depending on pressure and strength of external electric field. Recent investigations have demonstrated a great potential of microwave discharges to ignite air/fuel mixtures at low-pressure $[19,20]$. In these applications, the microwave discharge has a form of thin plasma filaments driven by highly non-linear ionizing waves (streamers) [21]. The restrictions imposed by aerospace technology on a power of electromagnetic beam and flow pressure lead to application of a deep sub-critical streamer discharge. The temperatures in the discharge region varies from 1000 to $2000{ }^{\circ} \mathrm{C}[22]$. It is possible to ignite the streamer discharge at the initial strength of electrical field, $E_{0}$, which is significantly lower than energy leading to air breakdown, $E_{c}$. However, the resonant method of amplifying the electric field to be applied in this case.

Previous experiments demonstrated that the microwave discharge has a streamer form at high pressures in the sub-critical (if $E_{0} / E_{c}<1$ ) and deep sub-critical (if $E_{0} / E_{c} \ll 1$ ) fields. In these cases, the temperature of plasma streamer channels that form the discharge has the scale no less than $2000 \mathrm{~K}$. In principle the realization of such temperature is enough for stable fuel ignition.

Multi-scale streamer discharge simulation is performed in [21]. A deep sub-critical streamer discharge is used in [22] to ignite air/propane mixture in the supersonic flow at high altitudes. Non-premixed hydrocarbon fuels in high-speed air flows $(\mathrm{M}<2)$ are considered in $[17]$. 
A nano-second pulsed discharge located between two fuel jets is used to ignite jet flames in sub- and supersonic crossflows without the use of additional devices (e.g., cavities or backsteps) for flame holding [28]. Hydrogen and ethylene jets are injected into an oxygen freestream with a Mach number $\mathrm{M}=1.7-2.4$. A configuration combining an upstream subsonic oblique jet and a downstream sonic transverse jet is shown to provide adequate flow conditions for jet flame ignition assisted by the plasma discharge [29].

The experimental study focuses on the use of sub-critical streamer discharge to provide a stable ignition and efficient combustion of air/fuel mixtures in low- and high-speed flows. To provide ignition of the mixture at the strength of the external electric field lower than the critical one, a metallic vibrator is applied. Qualitative (flame structure) and quantitative (size of combustion region, temperature distributions) characteristics of the flame zone are provided for different flow speeds and equivalence fuel/air ratios, and conditions of discharge initiation with metallic microwave vibrator are studied. Combustion efficiency of air/propane mixture in low- and high-speed flows at various flow speeds and fuel/air ratios is analyzed.

\section{Experimental setup}

The experiments are carried out using the test rig designed at the Moscow Radio-Technical Institute of Russian Academy of Science (MRTI RAS). The test rig is similar to that used and described in [22]. The test rig includes the vacuum part, aerodynamic part forming lowor high-speed flow, microwave part forming electromagnetic beam, fuel supply line, elements of discharge initiation and measuring equipment.

The test rig presented in the Figure 1 shows the flow channel with a high-speed air valve at the inlet, microwave generator waveguide, pressure and temperature measurement system and exhaust system placed in a vacuum chamber [22]. A manifold for propane injection to the flow channel is placed before air valve. The mass flow rate is controlled by fuel valve and pressure in the tank. The experimental setup is equipped with Phantom v.251 high-speed camera (a speed is 510000 frames/s), a number of fast-response pressure transducers, photo-sensors and current voltage sensors. The measuring equipment includes manovacuummeters to measure static pressure in the working chamber with accuracy \pm 1.5 torr, high-speed electronic sensors to measure pressure variation in the working chamber, Pitot tube with corresponding electronic scheme to measure stagnation pressure and thermocouples to measure flow temperature. The thermocouple and the pressure sensor signals are recorded with Instek GDS-830 oscilloscope (a typical speed up is 105 torr/s and accuracy is \pm 1.5 torr $)$.

The experimental tests are performed in a pulsed regime. Electromechanical valve is located at nozzle inlet. The triggering signal starts the oscilloscope measurement, and air valve opens after $0.2 \mathrm{~s}$. The microwave discharge is initiated after $0.1 \mathrm{~s}$ and burns $0.4 \mathrm{~s}$.

Vacuum part of the test rig consists of the working chamber and large hermetic tankreceiver. The working chamber is a horizontally located metal cylinder with flat edges and window on its side surface. The diameter of the working chamber is $0.7 \mathrm{~m}$, and its length is $1 \mathrm{~m}$. The working chamber has a volume of $0.4 \mathrm{~m}^{3}$. The receiver has a rectangular shape with dimensions of $1.25 \times 1.25 \times 2.5 \mathrm{~m}^{3}$ (its volume is $4 \mathrm{~m}^{3}$ ). There is a spherical transitional section between the working chamber and the receiver with a volume of $0.15 \mathrm{~m}^{3}$. The entire volume of the vacuum part is $4.2 \mathrm{~m}^{3}$. Pressure varies from 10 to 760 torr.

The high-speed flow is formed by the axisymmetric Laval nozzle. The nozzle throat is $23 \mathrm{~mm}$. The inlet diameter of the nozzle is $96 \mathrm{~mm}$, and the length of its converging part is $100 \mathrm{~mm}$. The outlet diameter of the nozzle is $30 \mathrm{~mm}$, and the length of its diverging part is 


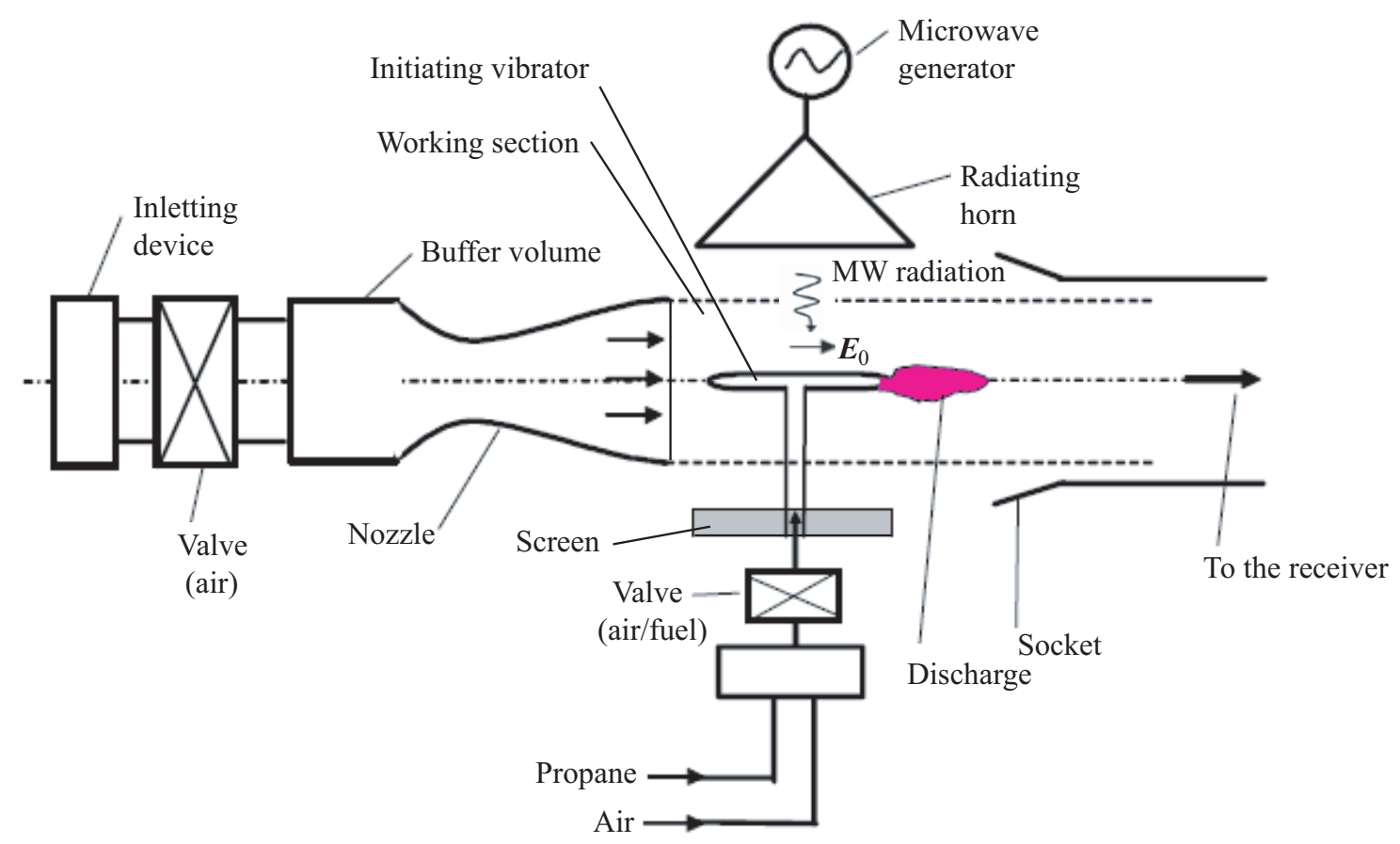

Figure 1. Test rig

$80 \mathrm{~mm}$.

The air speed at the nozzle outlet varies from 10 to $500 \mathrm{~m} / \mathrm{s}$. The flow is imposed by the pressure difference between inlet section of the nozzle and vacuum chamber. The total pressure at the inlet section of the nozzle is fixed at 750 torr. The total temperature is $300 \mathrm{~K}$. The static pressure in the working chamber varies from 30 to 150 torr. Supersonic jet is formed if a static pressure in the working chamber is less than 380 torr. For typical experimental conditions, the Mach number is 2 and flow speed is $500 \mathrm{~m} / \mathrm{s}$, static pressure in the working chamber is 97 torr, air temperature is $160 \mathrm{~K}$, the concentration of molecules is $6 \times 10^{18} \mathrm{~cm}^{3}$. The supersonic flow has a core with typical of $1.8 \mathrm{~cm}$ at a distance of $12 \mathrm{~cm}$ from the nozzle exit. The pressure in the working chamber is maintained constant during 1 $\mathrm{s}$, and then it starts to grow.

The working chamber and the receiver are connected by conic-cylindrical section. This section moves along the centerline of the chamber. It is mounted at different distances from the nozzle exit varying from 0.05 to $0.5 \mathrm{~m}$. The internal diameter of the cylindrical section is $0.07 \mathrm{~m}$, and its length is $0.7 \mathrm{~m}$. The conical section is $0.22 \mathrm{~m}$ long with a maximum inlet diameter $0.14 \mathrm{~m}$. The conic-cylindrical section is installed and configured in a way to prevent the backward air flow from the receiver to the working chamber. The parameters of the jet are kept constant for a time of about $2 \mathrm{~s}$.

Electromagnetic beam is generated with a magnetron. Its output power is $1.5 \mathrm{~kW}$, and wavelength is $\lambda=12.3 \mathrm{~cm}$ (this wavelength is one of the most common for microwave generating devices [30]). A typical outlet area of magnetron is $9 \times 9 \mathrm{~cm}^{2}$. Linearly polarized electromagnetic beam formed in the working chamber is normal to flow directio. The vector of electrical component of electromagnetic field $\boldsymbol{E}_{0}$ is parallel to flow velocity and has a magnitude of $E_{0}<7.2 \mathrm{kV} / \mathrm{cm}$ at the focus. The transverse distribution of the intensity of electromagnetic radiation of the beam is close to Gaussian with a characteristic size of 5 $\mathrm{cm}$. It is uniform along the beam centerline over a length of a few centimeters. The pulse duration is $40 \mu \mathrm{s}$.

A tubular electromagnetic vibrator with a quartz head, shown in the Figure 2, is used to 
induce a sub-critical streamer discharge. A propane is pumped through the tabular vibrator, and the tube is placed in the external air flow. Total temperature is measured at the distance of $3 \mathrm{~cm}$ from the vibrator aft end. The vibrator is a copper pipe with the length $2 L$ and flat faces. The outer diameter of the vibrator is $4 \mathrm{~mm}$. The vibrator is placed horizontally (its axis is aligned with the direction of air flow) and symmetrically with respect to the direction of microwave beam. The electromagnetic vibrator is mounted on a pylon (it 10 $\mathrm{mm}$ length and $2 \mathrm{~mm}$ thick). The blockage area is about $14.5 \%$. The pylon is placed on a flat conducting screen. The distance from the vibrator centreline to the screen is $31 \mathrm{~mm}$.

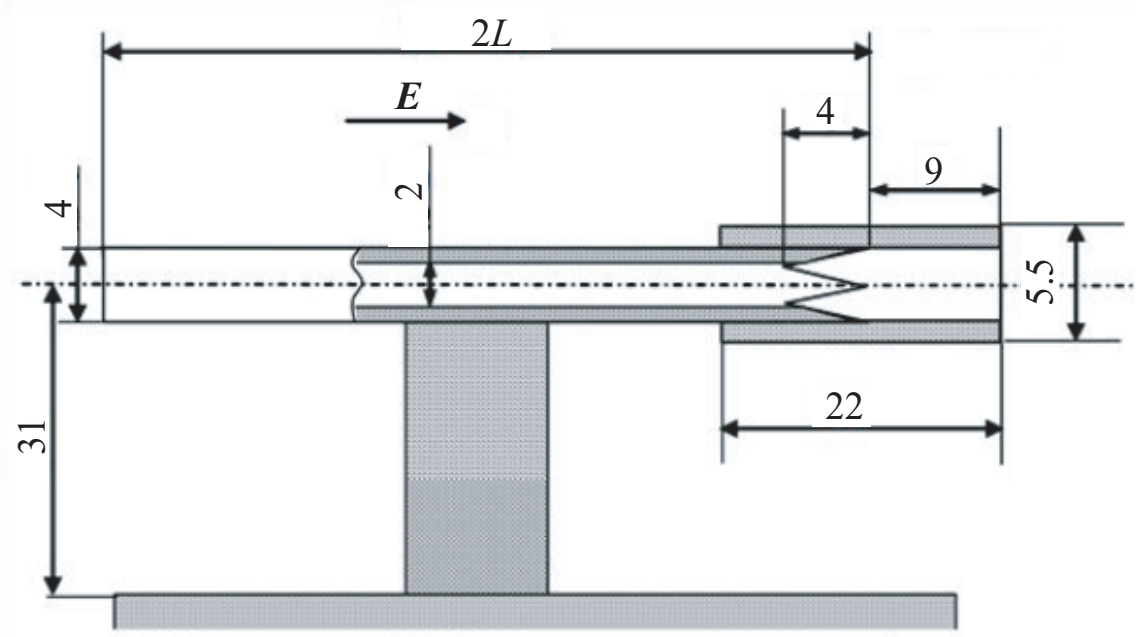

Figure 2. A tubular vibrator (lengths are shown in millimeters)

\section{Results and discussion}

The study of the deep sub-critical streamer discharge and its abilities to ignite air/fuel mixture is carried out for wavelength of microwave radiation $\lambda=12.3 \mathrm{~cm}$. The initial strength of the electric field is $E_{0}=140 \mathrm{~V} / \mathrm{cm}$. Thermocouple is located at the length of $3 \mathrm{~cm}$ from the initiator aft end. The static pressure in air stream is fixed at 114 torr. Measurements are performed for lean $(\alpha<1)$ and rich $(\alpha>1)$ air/fuel mixtures. Ignition region of air/propane mixture corresponds to the interval $0.56<\alpha<2.5$.

\subsection{Effect of fuel/air ratio}

Equivalence fuel/air ratio is defined as the ratio of actual fuel/air to stoichiometry for a given mixture

$$
\alpha=\frac{m_{f} / m_{a}}{\left(m_{f} / m_{a}\right)_{s}}
$$

where $m_{f}$ is the mass of fuel, $m_{a}$ is the mass of air. The value of $\left(m_{f} / m_{a}\right)_{s}=1 / 17.3$ corresponds to the stoichiometric mixture of propane and air $(\alpha=1), \alpha>1$ corresponds to the rich mixture and $\alpha<1$ corresponds to the lean mixture.

The experimental results for air/propane mixture are shown in the Figure 3. Flow velocity is $30 \mathrm{~m} / \mathrm{s}$, and fuel burning is controlled from the temperature measurements with a thermocouple. The microwave discharge is ignited in $0.1 \mathrm{~s}$ after air and fuel valves opening. The discharge burns during $0.4 \mathrm{~s}$. The propane valve is closed in $0.5 \mathrm{~s}$ and the air valve is 
closed in $0.8 \mathrm{~s}$. The right fragments show the temperatures at the stagnation point. Vertical straight lines correspond to the temperature of $100{ }^{\circ} \mathrm{C}$. The flame is clearly visible in the left fragments even for the case of a lean air/fuel mixture.
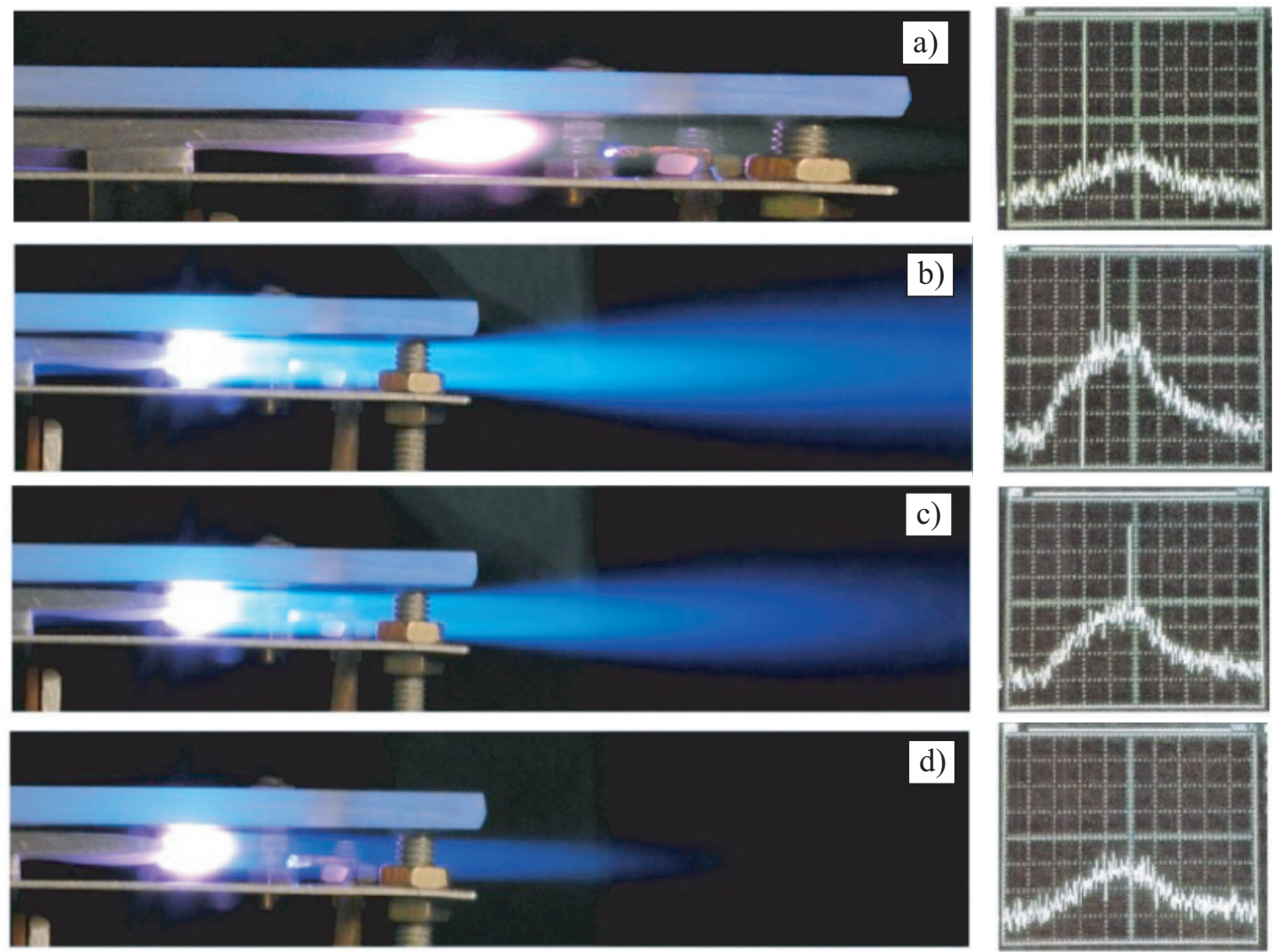

Figure 3. Streamer discharge in air flow of $30 \mathrm{~m} / \mathrm{s}$ : discharge in air (a), combustion of stoichiometric mixture with pressure of 3.3 bar (b), combustion of lean mixture for $\alpha=0.7$ with pressure of 1 bar (c), combustion of lean mixture for $\alpha=0.5$ with pressure of 0.3 bar $(d)$

Figure 3a shows the sub-critical streamer discharge in the air (the mixture does not burn). The flame has a pink color. A bright torch glowing in blue (Figure 3b) is observed for initial stoichiometric ratio of air and fuel (this is typical for complete combustion of propane). The pink luminescence is visible only on the surface of the resonators. The area of temperature rise on the thermocouple readings has a curved shape typical for combustion. The time division value is $0.1 \mathrm{~s}$, and the temperature division value is $100{ }^{\circ} \mathrm{C}$. When the lean mixture with $\alpha=0.7$ is ignited, the length of the plume decreases, but the nature of combustion does not change significantly (Figure 3c). The flame is even more shortened, and the luminescence region becomes pinkish when a poor air/fuel mixture with $\alpha=0.5$ is supplied (Figure 3d). When a air/fuel rich mixture burns, the flame spreads in the transverse direction, and the lean mixtures $(\alpha<0.5)$ burn in the wake of the streamer discharge attached to the vibrator.

The vibrator is placed in the air flow at a speed varying from 5 to $30 \mathrm{~m} / \mathrm{s}$ (direction of air flow is from the left to the right). The experimental observations are shown in the Figure 4 for air velocity fixed at $11 \mathrm{~m} / \mathrm{s}$. Photographs are arranged in rows from left to right in each line and from top to bottom along lines. The first left picture in the top line corresponds to the burning of the microwave streamer discharge in a clean air. The equivalence fuel/air ratio corresponding to the picture is presented at the bottom of each fragment. They show that the experiments began with a rich mixture with $\alpha=1.4$ and ended with a lean mixture 
with $\alpha=0.24$. Oscillograms shown in the Figure 4 are inverted, and upper horizontal line corresponds to zero level of signal. The time division value is $0.1 \mathrm{~s}$, and the temperature division value is $122.5^{\circ} \mathrm{C}$. A distance between initiator edge and thermocouple edge is 300 $\mathrm{mm}$. The discharge is ignited inside the quartz tube on the sawtooth edge of the metal tube, which plays the role of a resonator. Ignition of the mixture occurs inside the tube. A torch of burning fuel mixture is visible with a thermocouple placed in it, the readings of which are shown on the right of each fragment. The temperature scale is pointing down. The first fragment shows the photo and thermocouple readings for streamer discharge in quiescent air. For $\alpha=0.24$, the temperature rise is larger than when discharged in clean air (combustion takes place). To estimate the nature of flame propagation at different fuel/air ratios, temperature measurements across the jet are carried out. Measurements show that for $\alpha=0.57$ the flame front propagates in the transverse direction, and for $\alpha=0.52$ (below the lean flame propagation limit) the mixture burns in the wake of the discharge.

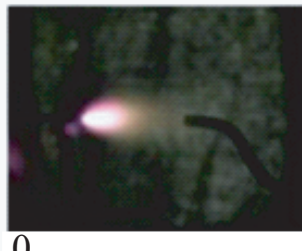

0

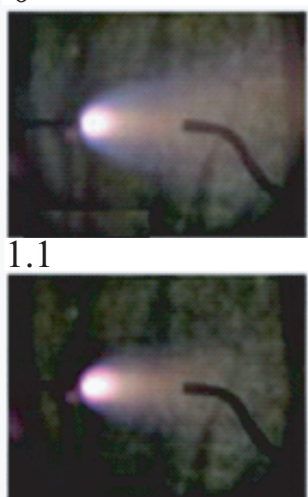

0.8

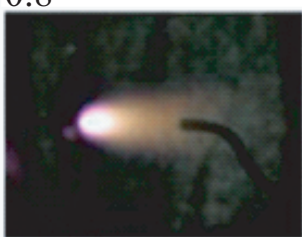

0.57

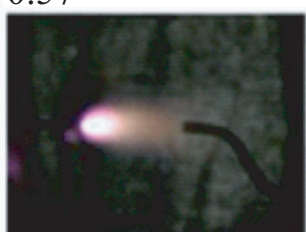

0.42

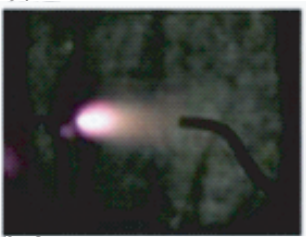

0.3
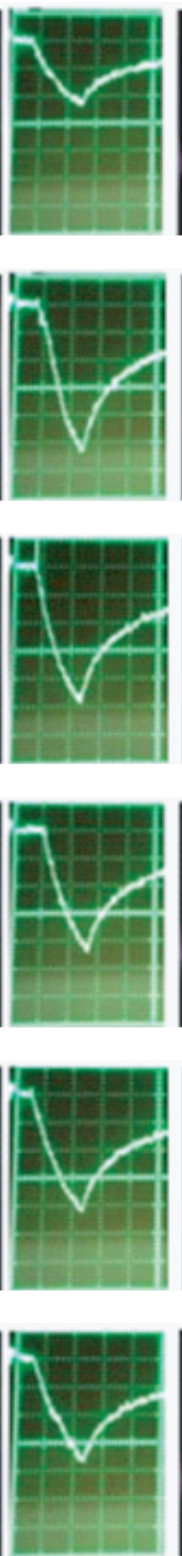

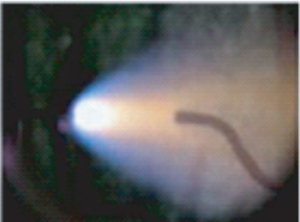

1.4

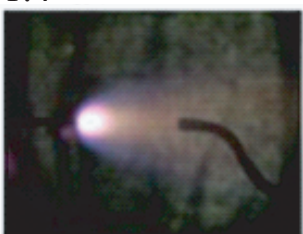

0.99

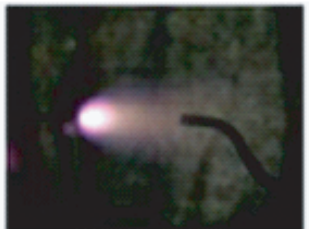

0.71

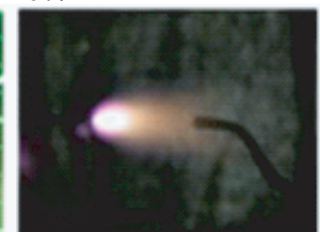

0.52
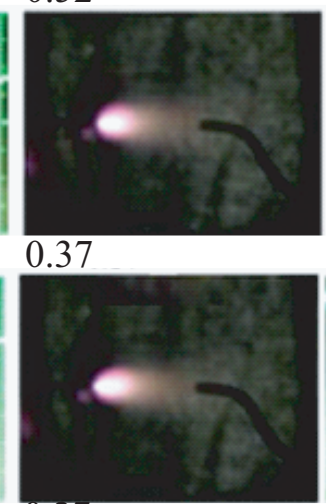

0.27
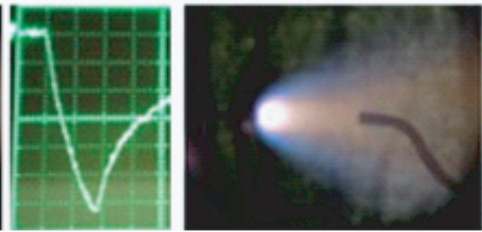

1.2
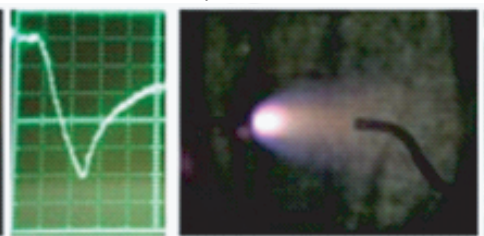

0.89
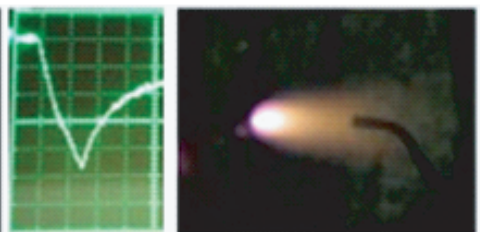

0.64
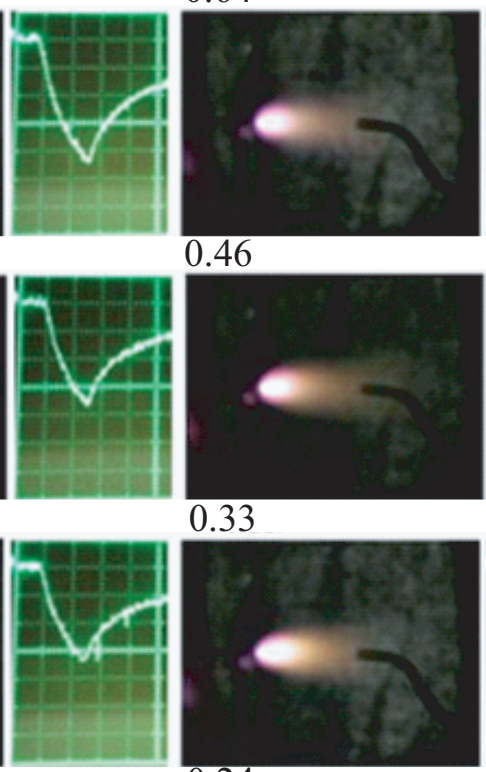

0.46

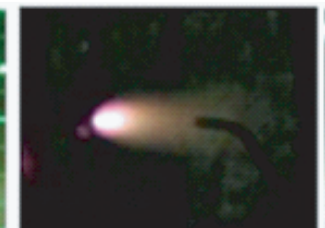

0.33

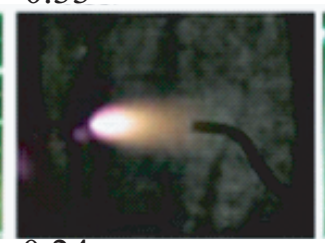

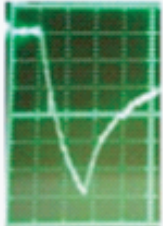
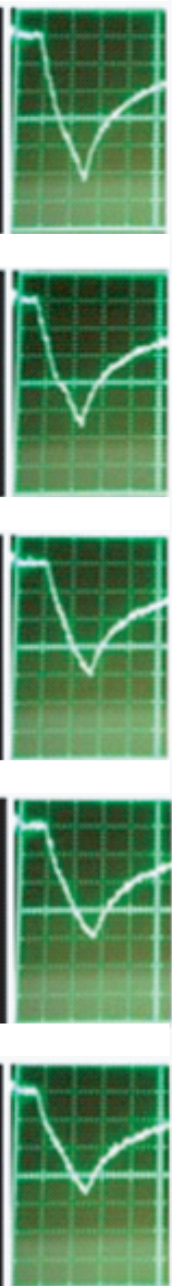

0.24

Figure 4. Ignition of air/propane mixture with sub-critical streamer discharge attached to the tubular vibrator at flow speed of $11 \mathrm{~m} / \mathrm{s}$ for different equivalence fuel/air ratios

For the described experimental sequence of pictures with number $n$, the equivalence 
fuel/air ratio is defined as

$$
\alpha=17.3 \frac{\rho_{0 f}}{\rho_{0 a}}\left[\frac{p_{s}}{p_{0 f}\left(1-\frac{\Delta p_{b}}{p_{s}}\right)^{n}-1}\right]^{-1},
$$

where $\rho_{0 f}=2.2 \times 10^{-3} \mathrm{~g} / \mathrm{cm}^{3}$ and $\rho_{0 a}=1.23 \times 10^{-3} \mathrm{~g} / \mathrm{cm}^{3}$ are density of propane and density of air at normal atmospheric conditions, $p_{0 f}$ is the total pressure of propane, $p_{s}$ is the total pressure of the air/fuel mixture, $\Delta p_{b}$ is the pressure drop during the time of experimental measurements. In the experiments, $p_{0 f}$ is fixed at 38 torr.

The ignition of the air/propane mixture corresponds to the equivalence fuel/air ratio between $\alpha=0.6$ and $\alpha=2.77$. The Figure 5 shows structure of the streamer discharges in various mixture $(\alpha=1.4$ is a rich mixture, $\alpha=1.1$ is a mixture with almost stoichiometric fuel/air ratio, $\alpha=0.24$ is a lean mixture, $\alpha=0$ is microwave discharge in a clean air). The mixture with the initial values of $\alpha=1.4$ and $\alpha=1.1$ burns in the whole diameter of the flow of the combustible mixture with a diameter of $3 \mathrm{~cm}$. The speed of flame front propagation in the direction normal to the stream is high at the leading front of the combustion region and substantially decreases. The lean mixture burns only in the wake of the streamer discharge, and the flame does not spread in the mixture in the direction normal to the flow.
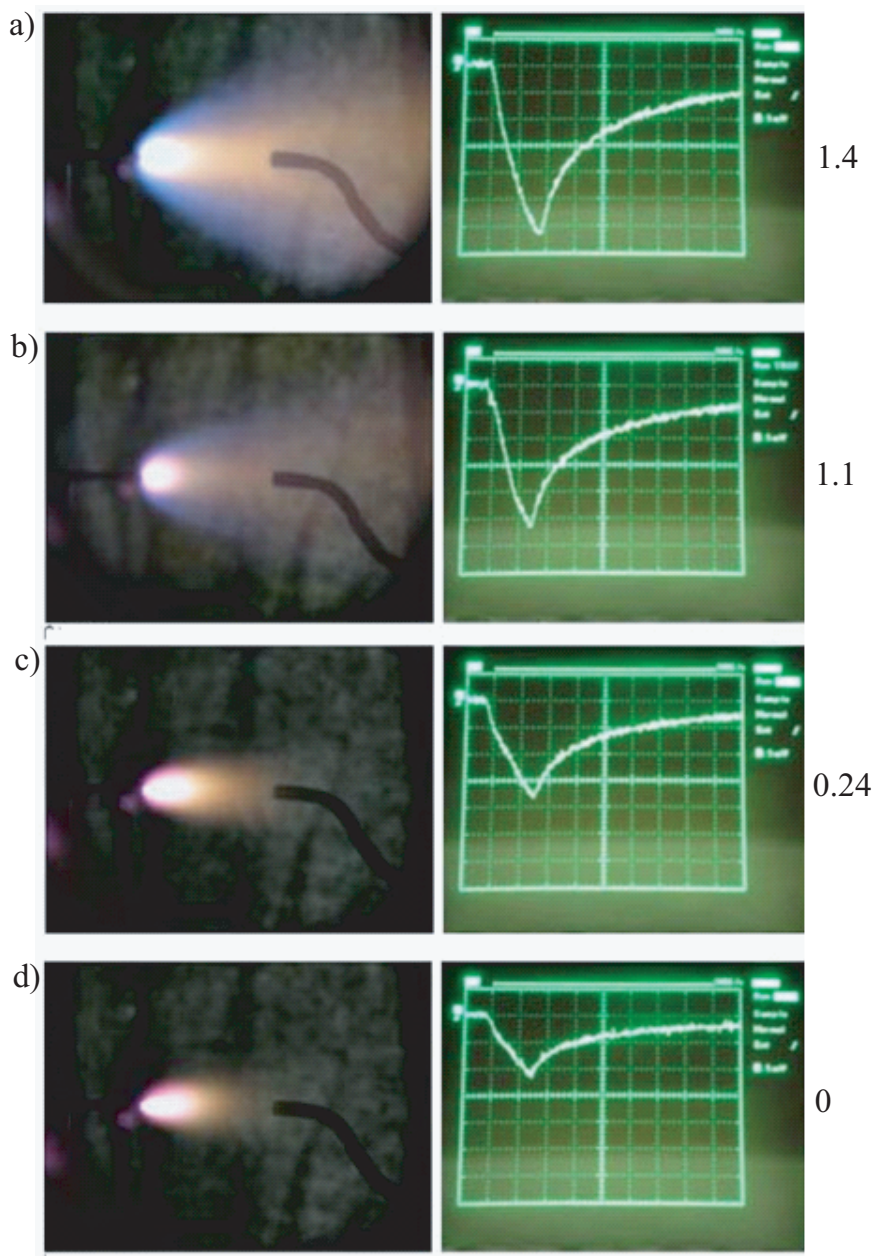

Figure 5. Ignition of air/propane mixture with the subcritical streamer discharge in rich mixture ( $a$ and $b)$, lean mixture (c) and streamer discharge in clean air $(\mathrm{d})$ 
As fuel/air ratio decreases in the initial mixture, the signal amplitude decreases (the waveforms are inverted). On the oscillograms, the vertical sensitivity is $5 \mathrm{mV} / \mathrm{div}$, and the horizontal scale is $0.1 \mathrm{~s} /$ div. When the streamer discharge is ignited, the voltage at the output of the meter starts to increase in time, and it drops at the end of discharge. The time of signal growth measured by oscillograms is $0.16-0.18 \mathrm{~s}$.

\subsection{Discharge structure}

Photographs of the streamer discharge and the combustible mixture ignited by it with different contents of propane are shown in Figure 6. The fragment of stoichiometric ratio burning in the microwave discharge of the air/propane mixture is shown on an enlarged scale. The burning cones of the mixture at the ends of the microwave streamers downstream indicate an increase in the speed of the combustion front in the presence of the microwave discharge to $150 \mathrm{~m} / \mathrm{s}$. Under normal conditions, this speed is of the order of $1 \mathrm{~m} / \mathrm{s}$.

a)

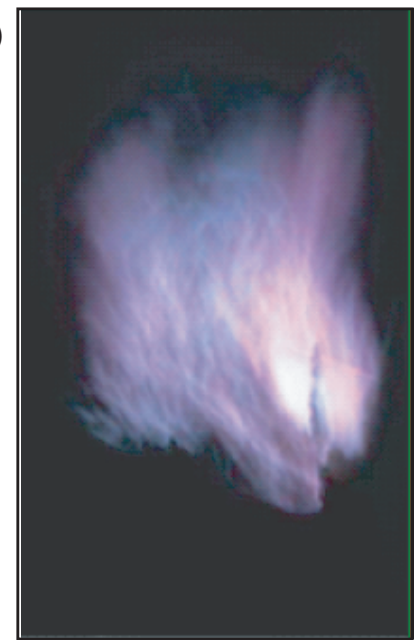

b)

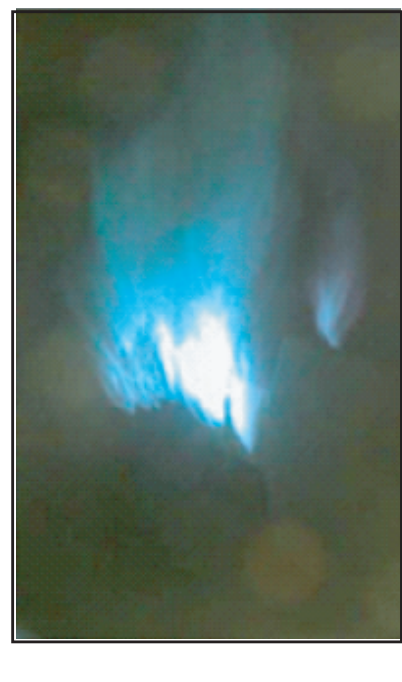

c)

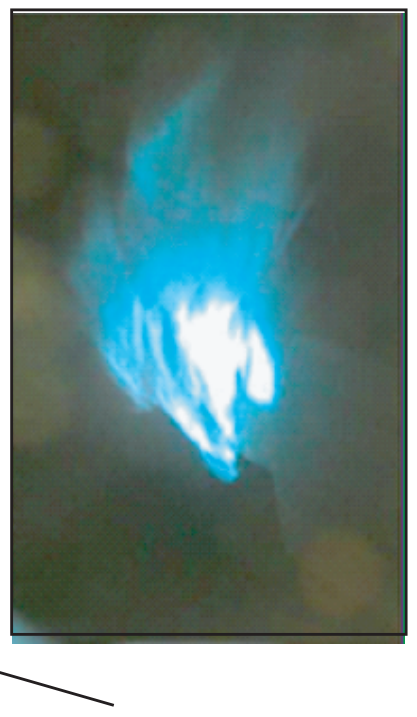

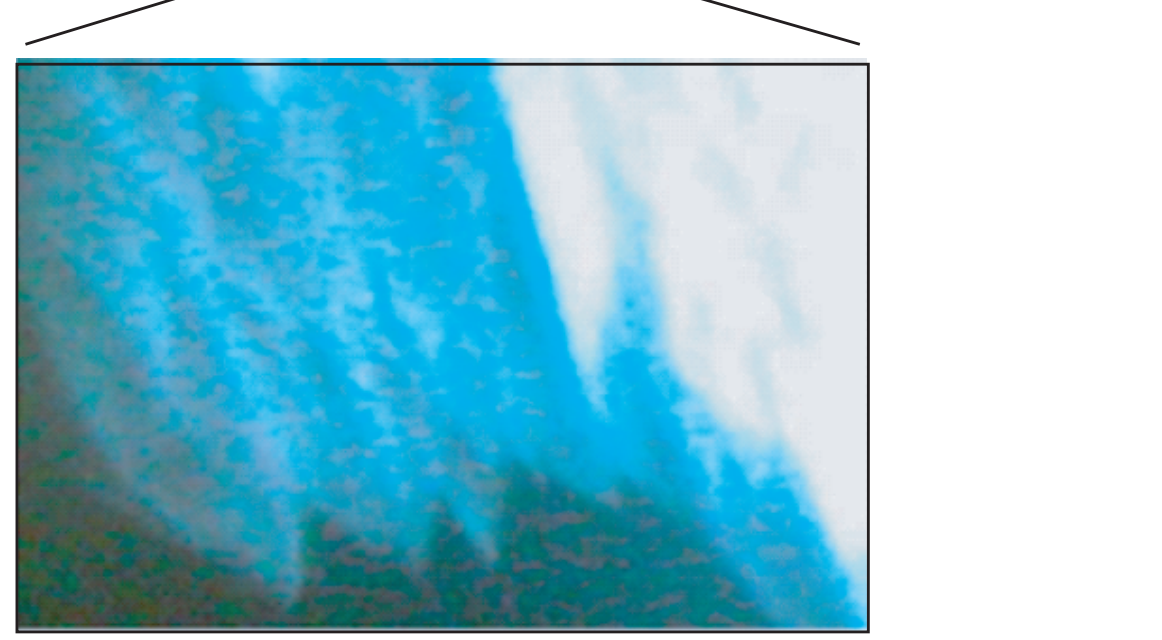

Figure 6. Structure of the streamer microwave discharge in lean (a), stoichiometric (b) and rich (c) air/propane mixtures

Figure 7 shows dependance of the maximum transverse size of the combustion region, $2 Y_{m}$, on fuel/air ratio. The zone of ignition air/propane mixture is shown below the graph. The burning region of a rich mixture extends over the entire cross section of its flow $2 Y_{m}=30$ $\mathrm{mm}$. As fuel/air ratio decreases, the size of $2 Y_{m}$ gradually decreases. This is due to the ejection of air into the plume from surrounding space. This leads to decreasing the propane 
fraction in the peripheral jet regions. When the fuel/air ratios are lower than the lean flame propagation limit of air/propane mixture, the size of $2 Y_{m}$ is equal to the maximum width of the discharge burning region in clean air.

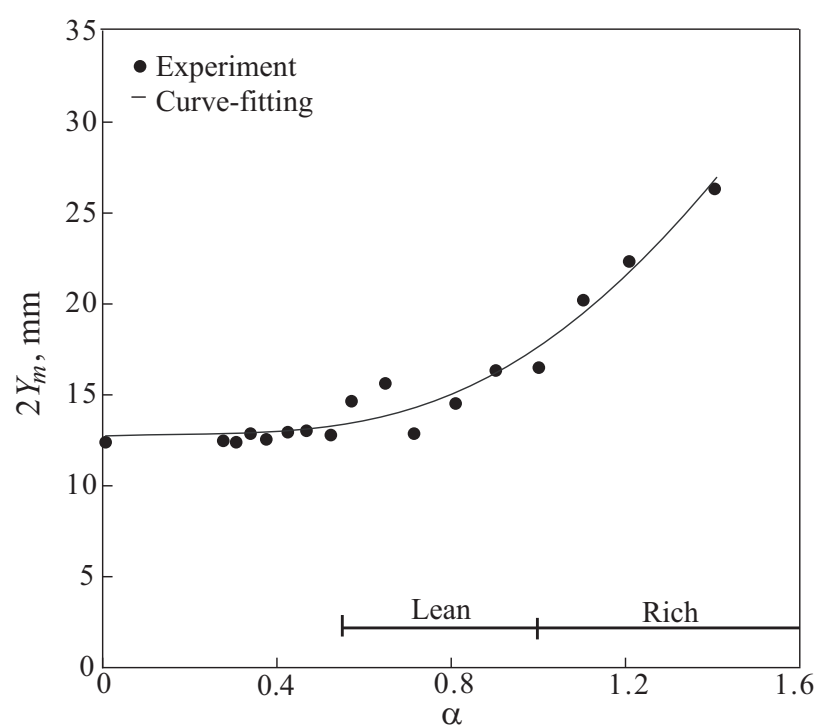

Figure 7. Dependance of the maximum transverse size of the combustion region on equivalence fuel/air ratio

Figure 8 shows dependance of the maximum longitudinal size of the combustion region, $X_{m}$, on fuel/air ratio. The traditional zone of ignition of air/propane mixture is shown below the graph. The graph shows the relative reduction in the length of the combustion region as the initial propane fraction in the mixture decreases.

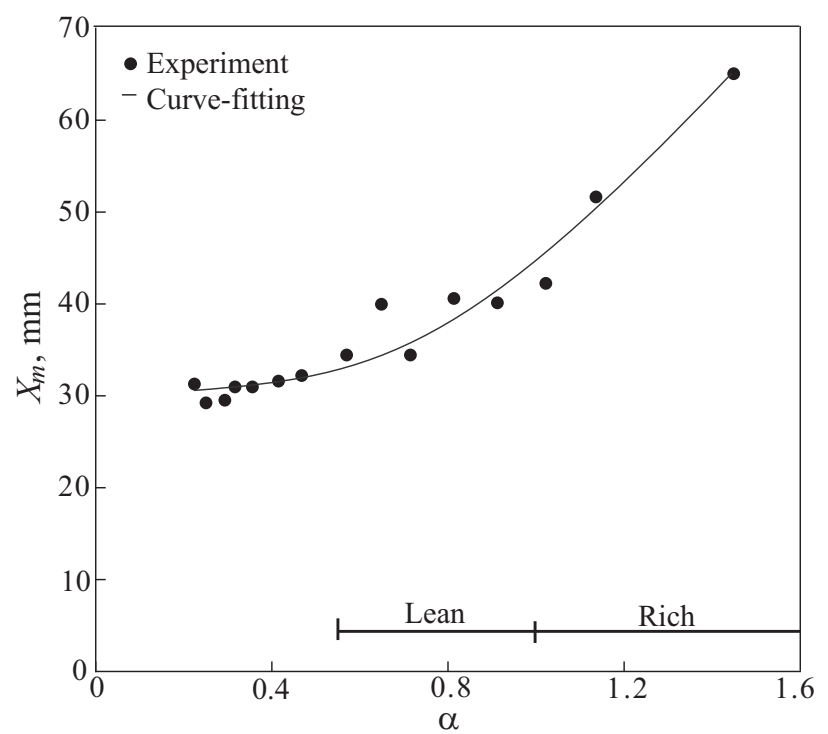

Figure 8. Dependance of the maximum longitudinal size of the combustion region on equivalence fuel/air ratio

Figure 9 shows dependance of the temperature in the combustion region, $\Delta T$, on fuel/air ratio. The air in the wake of the discharge heats up at $\Delta T_{\text {dis }}=510 \mathrm{~K}$. When burning in a propane jet ignited by a microwave discharge, the temperature rises approximately linearly with increasing fuel/air ratio. 


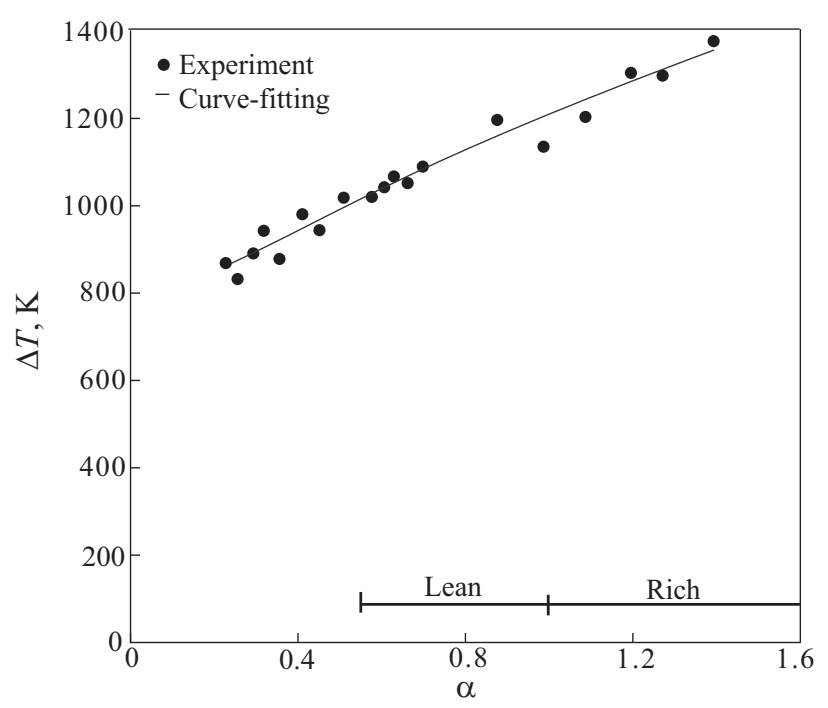

Figure 9. Dependance of the temperature in the combustion region on equivalence fuel/air ratio

The power of the microwave ration in experiments is $P=1 \mathrm{~kW}$. Taking into account a size of the radiating aperture of the beam forming horn $\left(9 \times 9 \mathrm{~cm}^{2}\right)$ and its opening angle, the beam in the discharge initiator has an area of $12 \times 12 \mathrm{~cm}^{2}$. The estimated initial strength of the electric field in this region is $E_{0}=70 \mathrm{~V} / \mathrm{cm}$, and the intensity of the beam is $\Pi=7$ $\mathrm{W} / \mathrm{cm}^{2}$. The jet at the nozzle outlet has a air velocity of $v_{f l}=11 \mathrm{~m} / \mathrm{s}$ with a typical diameter of $d_{\text {out }}=3 \mathrm{~cm}$ for the pressure of $p_{f l}=p_{c}=114$ torr at a reference temperature $T_{0}=300 \mathrm{~K}$. During the jet outflow time $\Delta t=0.5 \mathrm{~s}$, the mass flow rate of air entering the working chamber is $m_{\text {air }}=1.26 \mathrm{~g} / \mathrm{s}$. For stoichiometric composition of air/propane mixture, the mass flow rate of propane injected to air stream is $m_{C_{3} H_{8}}=m_{\text {air }} / 16=7.8 \times 10^{-2} \mathrm{~g} / \mathrm{s}$. For the given energy released from propane combustion $\left(Q_{\text {com }}=4.64 \times 10^{4} \mathrm{~J} / \mathrm{g}\right)$, the total combustion power is $P_{\text {com }}=3.5 \mathrm{~kW}$. It is assumed that the measured increase in air temperature in the wake of the discharge $\left(\Delta T_{d i s}=500 \mathrm{~K}\right)$ is the same as in the cross section of the plasma discharge region $\left(2 Y_{\text {dis }}=1.2 \mathrm{~cm}\right)$. Then, the heating power of the air in the discharge is $P_{d i s}=80 \mathrm{~W}$. The effective area of the region of interaction of the electromagnetic beam with the discharge plasma found from these estimations is $S_{\text {ef dis }}=12 \mathrm{~cm}^{2}$. It is significantly higher than the maximum area measured from the photographs $\left(S_{d i s}=2.5 \mathrm{~cm}^{2}\right)$.

The flow temperature is measured at a length of $3 \mathrm{~cm}$ from the aft end of the initiator. It is larger than the distance measured along the plasma stream of the microwave discharge region of $X_{d i s}=2.6 \mathrm{~cm}$, but significantly smaller than the length of the propane burning region, $X_{\text {com }}$, especially when the mixture is close to the stoichiometric initial composition. Measured in the experiment at $3 \mathrm{~cm}$, the increase in gas temperature during combustion of the initial stoichiometric mixture is $\Delta T_{\text {com }}=700 \mathrm{~K}$. Considering that this value is stored over the cross section of the jet, an estimation of the combustion power is $P_{\text {com }}=700 \mathrm{~W}$. The energetic estimations based on post-processing of the experimental data are shown in the Figure 10.

Thus, in experiments, the initiated deep sub-critical microwave discharge ignites the air-propane mixture and stabilizes its combustion region in a flow with a speed of $10 \mathrm{~m} / \mathrm{s}$. In this case, the power released in the discharge is an order of magnitude lower than the power released as a result of combustion of the air-propane mixture. A streamer microwave discharge ignites this mixture at a fraction of propane in it two times lower than the flame propagation limit. 


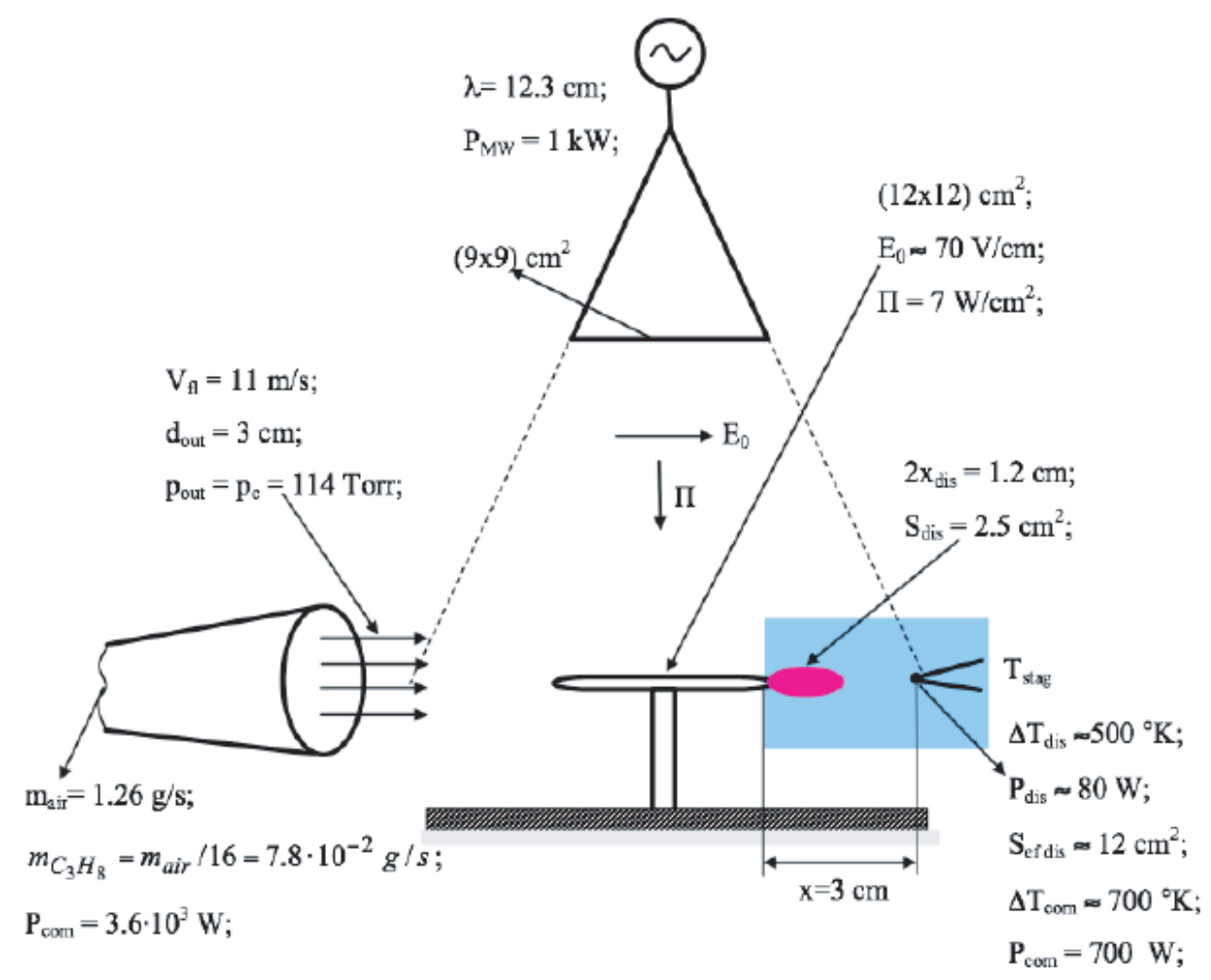

Figure 10. Estimations based on post-processing of the experimental data

\subsection{High-speed flow}

For a free streamer discharge, an estimation of growth speed of the streamer is [12]

$$
v_{S}=3.6 \cdot 10^{5}\left[\lambda \log \left(\frac{30 p}{E}\right)\right]^{-1 / 2},
$$

where $\lambda$ is the wavelength of microwave radiation $[\mathrm{cm}], p$ is pressure [torr], and $V$ is flow speed $[\mathrm{cm} / \mathrm{s}]$. The free electron diffusion coefficient is $D_{e}=10^{5} / p\left[\mathrm{~cm}^{2} / \mathrm{s}\right]$, and the critical value of electric field is $E_{c}=30 p[\mathrm{~V} / \mathrm{cm}]$. The radius of a head of plasma channel is determined by he depth of ionization front [31]

$$
a_{S}=\frac{11.1}{p}\left[\lambda \log \left(\frac{30 p}{E}\right)\right]^{1 / 2} .
$$

A streamer grows on the aft-end end of the vibrator, and the strength of the electric field does not exceed one leading to air breakdown. In a high-speed air flow, the attached streamer discharge is oriented downwards a stream. The radius of plasma channel of attached streamer discharge is limited by radius of the aft end of tabular vibrator providing the local rise of an electric field above the critical one. For the half-wavelength metal vibrator, oriented along a vector of an electric field, the factor of increase of a field is about $4 a$ [31], where $a$ is the radius of curvature of vibrator aft end. The radius of attached discharge is

$$
a_{S}=\frac{\lambda}{4} \frac{E_{0}}{E_{c}},
$$

For the attached streamer discharge, the heating parameter is determined by flow pressure 
and speed of flow

$$
q=4 \cdot 10^{3} \frac{p}{V} .
$$

Post-processing of experimental data shows that propane in the mixture burns almost completely for $\alpha=1.1$. An experiment with $\alpha=0$ makes it possible to estimate the effective area of the energy release of discharge plasma in the microwave wave. It is equal to $12 \mathrm{~cm}^{2}$. This area significantly larger than the maximum area of the discharge region. Colors of discharge region in propane (blue) and air (pink) are different. This is visible in the photos where the color of the discharge region changes from blue to pink if propane fraction in the mixture decreases.

Temperature measurements for streamer discharge in a free air stream and air/propane jet for $\alpha=0.11$ are presented in the Figure 11. Mach number varies from 0.3 to 0.9 due to changing of pressure in the receiver. The temperature rise in the fuel mixture is higher than in air if $\mathrm{M}<0.9$. Burning takes place, although the flame is not visible. The luminescence is blue and is not pink as in discharge in clean air. At low speeds $(\mathrm{M}<0.5)$, the fuel burns completely. At higher Mach numbers $(\mathrm{M}>0.6)$, the tube length must be increased to provide a complete burn of propane. The effect of thermal blocking of the tube takes place near values of $\mathrm{M}=0.55$ (Damkohler number reaches its critical value of 0.335 ), and flame slakes.
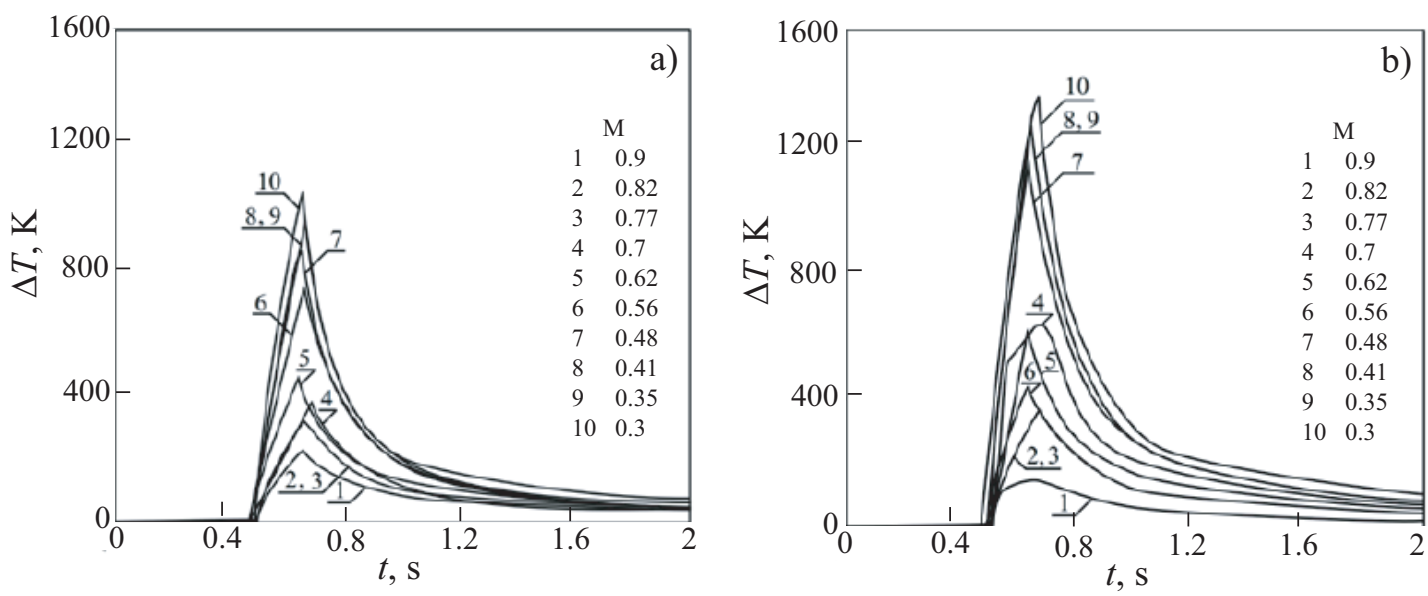

Figure 11. Temperature measurements for streamer discharge in quiescent air (a) and streamer discharge ignited in air/propane stream (b) for different Mach numbers: 0.9

(1), 0.82 (2), 0.77 (3), 0.7 (4), 0.62 (5), 0.56 (6), 0.48 (7), 0.41 (8), 0.35 (9), 0.3 (10)

Propane in the mixture at $\alpha=1.4$ and $\alpha=1.1$ is ignited and burns in the entire cross section of the jet, while at $\alpha=0.24$ it burns practically only in the wake of the discharge region. Estimations of the flame propagation velocity in the mixture in the zone adjacent to the discharge region from the photo of the propane combustion for $\alpha=1.4$ gives $10 \mathrm{~m} / \mathrm{s}$, which is significantly larger than those with uninitiated flame propagation.

The experimental results corresponding to the propane injection into a wake of air flow through the tubular vibrator are shown in the Figure $12\left(E_{0}=140 \mathrm{~V} / \mathrm{cm}, \lambda=12.3 \mathrm{~cm}\right)$. In this case, combustion continues at supersonic speeds although the flame is weakening. Ultraviolet radiation from the discharge region significantly affects molecular composition of the mixture. The air/propane mixture is ignited and burns even in the case when the fuel fraction in the mixture is much lower than the lean flame propagation limit. In the discharge region, the flame propagation velocity significantly increases, and burning time of the fuel is reduced. 


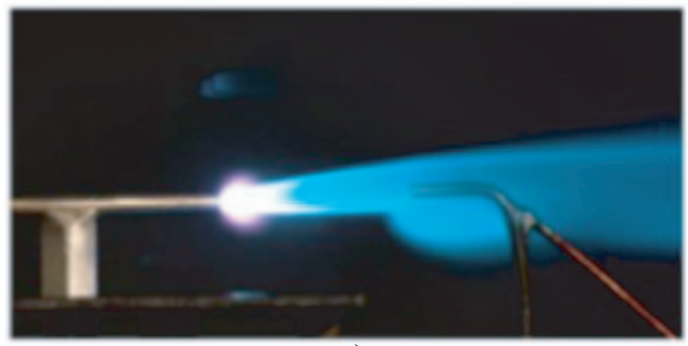

a)

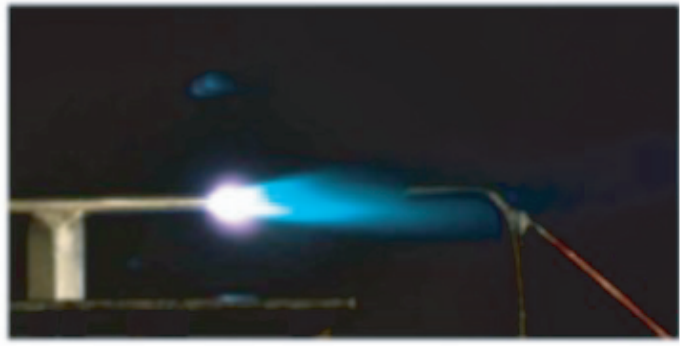

c)

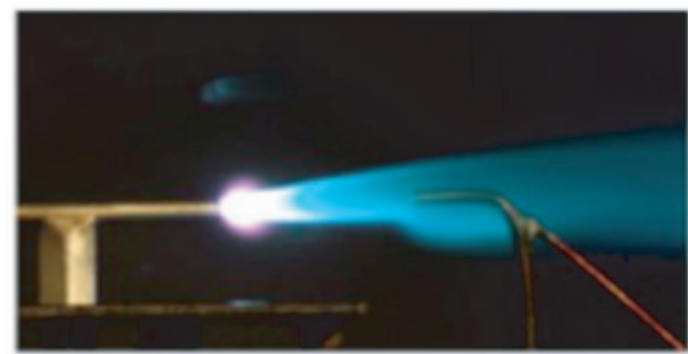

b)

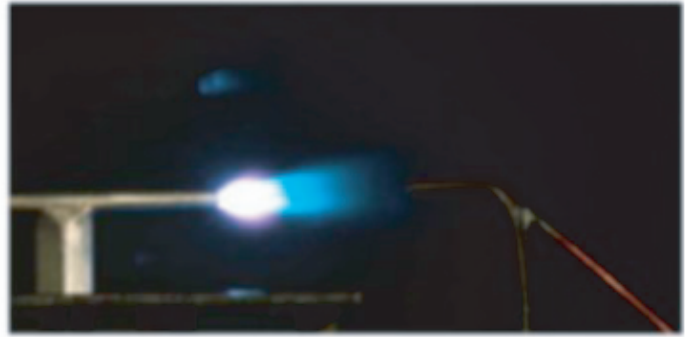

d)

Figure 12. Combustion of air/propane in the air flow induced by sub-critical streamer discharge at various flow velocities: $12 \mathrm{~m} / \mathrm{s}(\mathrm{a}), 30 \mathrm{~m} / \mathrm{s}$ (b), $85 \mathrm{~m} / \mathrm{s} \mathrm{(c),500} \mathrm{m/s} \mathrm{(d)}$

The contours of temperature in the cross section of supersonic flow is shown in the Figure 13 at distance of $1.4 \mathrm{~cm}$ from the vibrator. Noticeable temperature increase is 70 $100{ }^{\circ} \mathrm{C}$. Figure 13 a corresponds to the streamer discharge initiated in a supersonic air flow. Figure 13b shows the case when propane is injected to the discharge region. The beam power is $1.5 \mathrm{~kW}$ in both cases. The mass flow rate of propane is $8.5 \times 10^{-3} \mathrm{~g} / \mathrm{s}$. The power released from complete combustion of the propane is about $390 \mathrm{~W}$. The experimentally measured stagnation pressure and stagnation temperature show that power of $158 \mathrm{~W}$ is supplied by the microwave beam to air heating in the discharge region. It is about $12 \%$ of the power of generator of microwave beam. The power additionally supplied to the flow heating due to propane burning is about $278 \mathrm{~W}$ demonstrating that about $72 \%$ of propane burns in the discharge region.

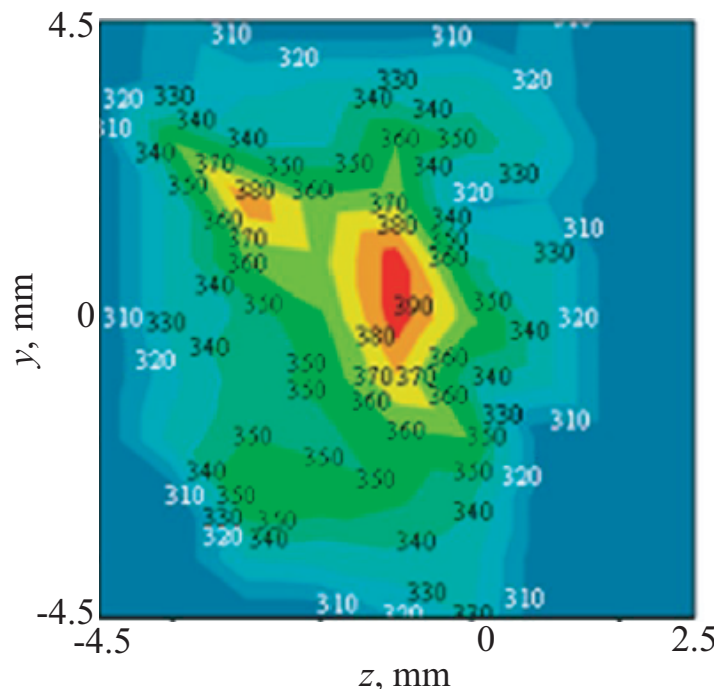

a)

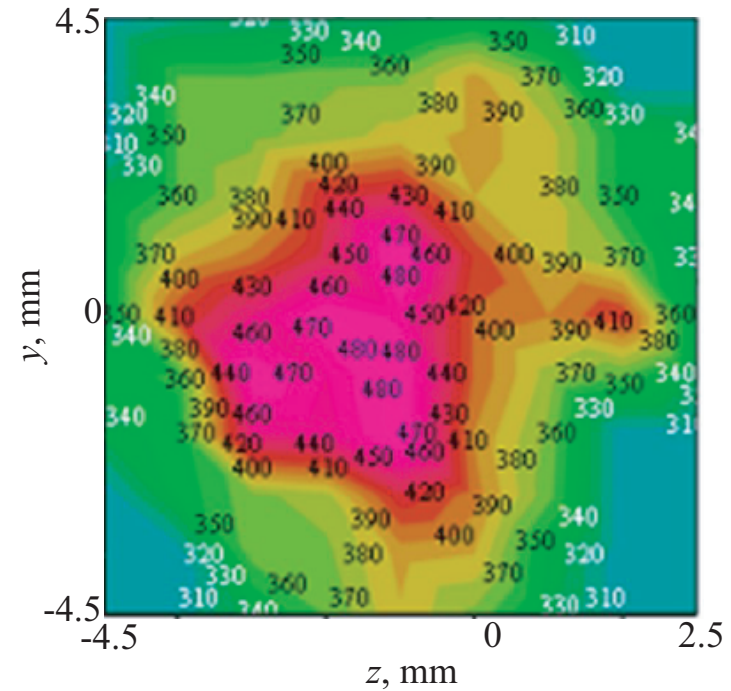

b)

Figure 13. Temperature contours in the cross section of supersonic flow: air is injected into discharge area through the vibrator (a) and air/propane mixture is injected into discharge region (b) 
Experimental results for high-speed flow is shown in the Figure 14. The flow speed is fixed at $500 \mathrm{~m} / \mathrm{s}$ (Mach number is 2). The plume is short, and propane combustion is observed for stoichiometric mixture (blue glow in the Figure 14a). For the lean mixture blue glow is till visible, however pink color appears (Figure 14b). For the poor lean mixture, the flame is not visible, and just thermocouple measurements confirm combustion process.
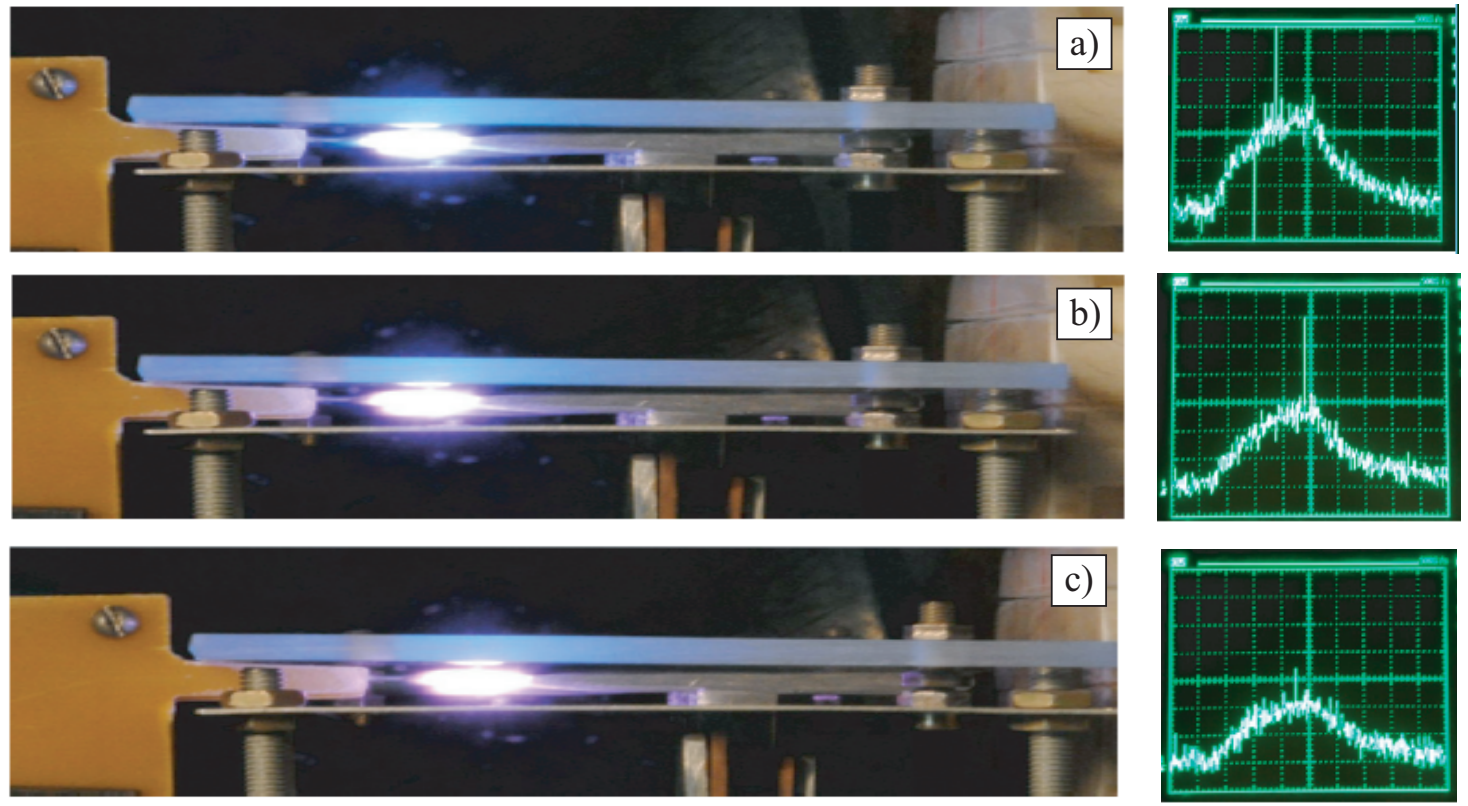

Figure 14. Streamer discharge in a flow of $500 \mathrm{~m} / \mathrm{s}$ : combustion of stoichiometric mixture at initial pressure of 3.3 bar (a), combustion of lean mixture for $\alpha=0.7$ at pressure of 1 bar (b), combustion of lean mixture for $\alpha=0.5$ at pressure of 0.3 bar (c)

The total pressure drops by $8-12 \%$ due to increase in air temperature in a flow with the microwave discharge. The total pressure slightly decreases by about $2 \%$ when propane is injected to the stream. Pressure drop between atmosphere and vacuum chamber has a small effect on total pressure. The pressure difference is used to form a supersonic flow, and variation of pressure affects stability of microwave discharge ignition, and does not affect the flow quantities. Variation of equivalence fuel/air ratio leads to a small variation of total pressure by about $1 \%$. Small changes in total temperature by 10-15 degrees are observed when a pressure difference varies from 60 to 150 torr. The pressure difference does not affect the air flow with microwave discharge and combustion of air/propane mixture induced by the streamer discharge. Increase in equivalence fuel/air ratio from 0.72 to 0.98 causes rise in total temperature by 60-80 degrees (pressure difference is fixed at 0.12). Further increase in equivalence fuel/air ratio from 1 to 1.2 rises the total temperature to $350{ }^{\circ} \mathrm{C}$ which is almost 100 degrees higher than for $\alpha=0.98$.

Sub-critical streamer discharge attached to the vibrator allows to ignite propane injected in high-speed flow. Combustion is distinguished by higher speed and fullness compared to point thermal ignition. Time of complete combustion for plasma-assisted combustion in 1050 times faster compared to diffusive combustion. Thermocouple shows temperature well below ignition temperature of air/propane mixture. The speed of the combustion front, initiated by a streamer discharge, is 2-4 times higher in quiescent air and up to 20 times higher in the tube, compared to thermal ignition, which is similar in the amount of heat supplied to the fuel mixture. The mixture is ignited in the area occupied by the discharge plasma if the fuel/air ratio is lower than 0.5. Combustion takes place in a lean mixtures with a fuel/air ratio of about 0.1 when the fuel is pumped through the wake of discharge region. 


\section{Conclusion}

Ignition of fuel/air mixture induced by the sub-critical streamer discharge in low- and highspeed flows is studied experimentally. The experimental results confirm stable creation of the streamer discharge in sub- and supersonic air flows, and a steady burning of the fuel. The air flow velocity corresponding to stable plasma-assisted combustion is much higher than in propane combustion induced without plasma assistance.

In experiments, the sub-critical discharge initiated with metallic vibrator ignites the air/propane mixture allowing to stabilize its combustion in a low- and high-speed flows (flow speed varies from 10 to $500 \mathrm{~m} / \mathrm{s}$ ). In the cases considered in the study, the power released in the streamer is an order of magnitude lower than those released as a result of the mixture combustion. The streamer ignites the mixture with the fuel fraction which is two times lower than the lean flame propagation limit of the mixture. As propane fraction in the mixture decreases, the temperature of the combustion products decreases approximately linearly. If the propane fraction in the mixture is higher than the lean flame propagation limit, the flame front propagates along the flow of the mixture, going beyond the transverse size of the microwave discharge plasma region. In the region which is close to the microwave discharge and, especially, at the leading front of the combustion region, the flame propagation speed significantly higher than the flow speed. When the propane fraction in the mixture is lower than its lean flame propagation limit, the mixture burns only in the region of the discharge plasma.

The results obtained confirm the ability of sub-critical streamer discharge to induce a stable ignition of air/propane mixtures in low- and high-speed flows. The streamer discharge makes it possible to create multiple ignition points providing almost instantaneous ignition of entire volume of the mixture. The results show that the sub-critical streamer discharge can potentially be exploited in various combustion devices providing more rapid and efficient combustion. For example, the conventional spark ignition in the internal combustion engines could be replaced by microwave discharge, and streamer discharge can provide a short and fast transition from deflagration to detonation in the pulsed detonation engines.

\section{Acknowledgements}

This work was financially supported by the Ministry of Science and Higher Education of Russian Federation during the implementation of the project Creating a leading scientific and technical reserve in the development of advanced technologies for small gas turbine, rocket and combined engines of ultra-light launch vehicles, small spacecraft and unmanned aerial vehicles that provide priority positions for Russian companies in emerging global markets of the future, No. FZWF-2020-0015.

\section{References}

[1] Matveev I., Matveeva S., Serbin S. Design and preliminary result of the plasma assisted tornado combustor. AIAA Paper, 2007-5628.

[2] Davydov A.M., Gritsinin S.I., Kossyi I.A., Shikhman Y.M., Vinogradov V.A. Application of MW plasma generator for ignition of kerosene/air mixture. IEEE Transactions on Plasma Science, 2008, 36(6), 2909-2917, 2008. 
[3] Do H., Mungal M.G., Cappelli M.A. Jet flame ignition in a supersonic crossflow using a pulsed nonequilibrium plasma discharge. IEEE Transactions on Plasma Science, 2008, 36(6), 2918-2923.

[4] Matveev I., Serbin S. Investigation of a reverse-vortex plasma assisted combustion system. Proceedings of the ASME Heat Transfer Summer Conference, 8-12 July 2012, Puerto Rico, USA. New York: ASME, 2012. HT2012-58037, 133-140.

[5] Dresvin S., Zverev S., Ivanov D., Matveev I. High frequency induction plasma torches / Plasma Assisted Combustion, Gasification, and Pollution Control. Volume I. Methods of Plasma Generation for PAC. Outskirts Press, 2013, 373-462.

[6] Takahashi M., Ohnishi N. Shock formation by plasma filaments of microwave discharge under atmospheric pressure. Journal of Physics: Conference Series, 2016, 688, 012119.

[7] Goldfeld M.A., Pozdnyakov G.A. Ignition of hydrocarbon-air supersonic flow by volumetric ionization. Journal of Thermal Science, 2015, 24, 583-590.

[8] Ju Y., Sun W. Plasma assisted combustion: dynamics and chemistry. Progress in Energy and Combustion Science, 2015, 48, 21-83.

[9] An A., Wang Z., Yang L., Li X., Zhu J. Experimental investigation on the impacts of ignition energy and position on ignition processes in supersonic flows by laser induced plasma. Acta Astronautica, 2017, 137, 444-449.

[10] Leonov S.B. Electrically driven supersonic combustion. Energies, 2018, 11(7), 1733 (35 pages).

[11] Urzay J. Supersonic combustion in air-breathing propulsion systems for hypersonic flight. Annual Review of Fluid Mechanics, 2018, 50, 593-627.

[12] Khodataev K.V. Numerical modeling of the combustion, assisted by the microwave undercritical discharge in supersonic flow. AIAA Paper, 2005-0985.

[13] Grachev L.P., Esakov I.I., Khodataev K.V. Microwave streamer discharge in a supersonic air flow. Technical Physics, 1999, 44(11), 1271-1275.

[14] Esakov I.I., Grachev L.P., Khodataev K.V., Van Wie D.M. Investigation of the possibility of the application of the undercritical microwave streamer gas discharge for the ignition of a fuel in the jet engine. AIAA Paper, 2001-2939.

[15] Esakov I.I., Grachev L.P., Khodataev K.V., Van Wie D.M. Experiments on propane ignition in high-speed airflow using a deeply undercritical microwave discharge. AIAA Paper, 2004-0840.

[16] Adamovich I.V., Choi I., Jiang N., Kim J.-H., Keshav S., Lempert W.R., Mintusov E., Nishihara M., Samimy M., Uddi M. Plasma assisted ignition and high-speed flow control: non thermal and thermal effects. Plasma Sources Science and Technology, 2009, 18(3), 034 018-1-034 018-13.

[17] Klimov A., Bityurin V., Brovkin V., Vystavkin N., Kuznetsov A., Van Wie D. Optimization of plasma-assisted combustion. AIAA Paper, 2002-2250.

[18] Klimov A., Bityurin V., Kuznetsov A., Tolkunov B., Vystavkin N., Vasiliev M. External and internal plasma-assisted combustion. AIAA Paper, 2004-1014.

[19] Bulat M.P., Bulat P.V., Denissenko P.V., Esakov I.I., Grachev L.P., Volkov K.N., Volobuev I.A. Ignition of lean and stoichiometric air-propane mixture with a subcritical microwave streamer discharge. Acta Astronautica, 2018, 150, 153-161. 
[20] Denissenko P.V., Bulat M.P., Esakov I.I., Grachev L.P., Volkov K.N., Volobuev I.A., Upyrev V.V., Bulat P.V. Ignition of premixed air/fuel mixtures by microwave streamer discharge. Combustion and Flame, 2019, 202, 417-422.

[21] Duarte M., Bonaventura Z., Massot M., Bourdon A., Descombes S., Dumont T. A new numerical strategy with space-time adaptivity and error control for multi-scale streamer discharge simulations. Journal of Computational Physics, 2012, 231(3), 1002-1019.

[22] Vinogradov V.A., Komratov D.V., Chirkov A.Yu. Study of propane-air mixture combustion initiation by the formation of microwave plasma in a flow. Journal of Physics: Conference Series, 2018, 1094, 012027 (5 pages).

[23] Pilla G., Lacoste D.A., Veynante D., Laux C.O. Stabilization of a swirled propaneair flame using nanosecond repetitively pulsed plasma. IEEE Transactions on Plasma Science, 2008, 36(4), 940-941.

[24] Shibkov V.M., Aleksandrov A.A., Chernikov V.A., Ershov A.P., Shibkova L.V. Microwave and direct-current discharges in high-speed flow: fundamentals and applications to ignition. Journal of Propulsion and Power, 2009, 25(1), 123-137.

[25] Pertl F.A., Smith J.E. Electromagnetic design of a novel microwave internal combustion engine ignition source, the quarter wave coaxial cavity igniter. Proceedings of the Institution of Mechanical Engineers, Part D: Journal of Automobile Engineering, 2009, 223(11), 1405-1417.

[26] Phylippov Yu.G., Dushin V.R., Nikitin V.F., Nerchenko V.A., Korolkova N.V., Guendugov V.M. Fluid mechanics of pulse detonation thrusters. Acta Astronautica, 2012, $76(1), 115-126$.

[27] Smirnov N.N., Betelin V.B., Nikitin V.F., Phylippov Yu.G., Jaye Koo. Detonation engine fed by acetylene-oxygen mixture. Acta Astronautica, 2014, 104(1), 134-146.

[28] Do H., Im S., Cappelli M.A., Mungal M.G. Plasma assisted flame ignition of supersonic flows over a flat wall. Combustion and Flame, 2010, 157(12), 2298-2305.

[29] Yamamoto T., Tsuboi T., Iwama Y., Tanaka R. Combustion and reformulation enhancement characteristics of plasma-assisted spray combustion by microwave-induced non-equilibrium plasma. Energy and Fuels, 2016, 30(4), 3495-3501.

[30] Esakov I.I., Grachev L.P., Bychkov V.L., Van Wie D. Investigation of undercritical MW discharge with volumetrically developed streamer structure in propane-air supersonic stream. AIAA Paper, 2006-0790.

[31] Bulat P., Esakov I., Volkov K. The use of microwave discharge to induce ignition and detonation of air-fuel mixtures. Horizons in World Physics, 2018, 295, 139-190. 